\title{
EVALUATION OF BALL TYPE PRECISION ATTACHMENT FOR LOWER CLASS I KENNEDY CLASSIFICATION USING NEW COMPUTERIZED METHOD
}

\author{
Mona Moustafa Ebrahim Elramady*
}

\begin{abstract}
Introduction: Several types of attachments are accessible and they have been broadly used with removable partial/complete denture prosthesis and segmented fixed prosthesis. Yet, no single attachment is ideal for every case, so it is critical that the appropriate attachment should be selected for each individual situation.

Objectives: The present study aims to evaluate clinically the effect of using evaluation of ball type precision attachment for lower class I Kennedy classification using new computerized method (Image J program) by using panoramic x-ray and its effect on the bone height and changes at different sites.
\end{abstract}

Material and Methods: Twelve patients ranged from 45-60 year old (6 males and 6 female). Patients complaining from pain in some teeth, inability to masticate, chewing food and unsatisfactory esthetic. There are multiple missing teeth, the lower arch of the mandibular jaw is class I Kennedy classification without modification, fabrication of upper metallic casted partial denture and lower ball type precision attachment for lower bilateral distal extension Kennedy class I classification. Possessing of the upper and lower prosthesis, finishing, polishing and instruction for the patient. At the follow up periods starting (at first month with delivery of the finished denture, at six and twelve months).

Results: By comparing between gender grouping (male and female) by using ball type attachment, showed that the vertical height in the edentulous women were lower than that of the men. Markedly erosion or porosity of the mandibular bone cortex in dentate patient is increase with age. The statistical difference was evaluated with a $\mathrm{P}<0.05$ through $\mathrm{t}$-test which detected between different groups.

Conclusions: The use of ball type attachment for removable partial denture provide good retention support and stability of the partial denture improving function ability of mastication, showing and good esthetic acceptance for both gender groups.

KEY WORD: Ball attachment, metallic partial denture, overdenture, panoramic x-ray

\footnotetext{
* Lecturer at Prosthodontics Department of Prosthodontics, Pharos University, Alexandria City, Alex., Egypt
} 


\section{INTRODUCTION}

Treatment of partially edentulous arch that can be classified under Kennedy's class I and class II situations. Using of fixed partial denture is not indicated as a result of missing of distal abutment. In other prosthesis, it may be the suitable treatment option, but it is sometimes not feasible due to insufficient amount of bone and economic reason. So, in such cases an acrylic partial denture or a cast partial denture is generally preferred. The retention in cast partial dentures is made retentive by the use of both retainers and precision attachment components which could be extracoronal and intracoronal and also facilitate both esthetic and functional substitution of lost teeth. Magnetic and precision attachments have been successfully used in clinical practice, and so many clinicians feel that it is already part of everyday dentistry. Attachments provide some straight forward and effective solutions for the dentists working with removable prosthesis ${ }^{(1)}$.

An attachment is a connector includes two or more parts. One of them used for attached to a root, tooth, and the other part to prosthetic appliance ${ }^{(2)}$.

Precision attachments can be classified in to four main groups ${ }^{(3)}$.

1. Intracoronal attachments: are mainly used in connecting all the parts of fixed partial prostheses.

2. Extracoronal attachments which gave the partial denture is stability and retention.

3. Stud attachments. Take the design of ball and socket to give the overdenture its support and retention. The types of stud attachment which used are Swiss logic, ZAAG and Zest anchor. The advantages of stud are providing good oral hygiene and excellent crown root ratio with low profile.

4. Bar attachments provide good retention and support connecting the present teeth together.

\section{Indications and contraindications for precision retained partial denture}

The precision attachment give ideal design excellent function adequate physiologic function require excellent laboratory work ${ }^{(2)}$. It provides the desired esthetic excepted design for the patient due to its prevent to the buccal or labial direct retainer or clasp arm ${ }^{(2)}$.

The contraindications to the use of attachments in RPDs are the presence of short clinical crowns. In addition, sufficient height must be existing to be housed within the RPD framework or supportive acrylic resin while allowing an optimal artificial tooth position ${ }^{(3,4)}$.

Rehabilitation of partially edentulous arch can be challenging, when the remaining teeth are unable to withstand masticatory loadings in case of a distal extension or long span of the ridge. Fixed partial dentures (FPDs) were not indicated. Distal extension base partial dentures have passive effect on the remaining tissue which directed to use of other prosthesis that may be better biomechanically ${ }^{(5)}$.

Previous studies showed that the use of dissimilar denture base material show an obvious result on chewing ability and the occlusal force ${ }^{(6)}$, as a results of variations in bone reduction level on all sides of the terminal abutments. One of the indications of a practically stable masticatory function is the biting force is taken to assess different prosthetic appliances in dental treatment and its provide direct effect to a stable masticatory function ${ }^{(7)}$.

To perform retention, stability and prober distribution of stresses to the abutment teeth. The use of extracoronal attachments together with it is needed to give excellent esthetic and a functional results for remaining teeth and oral structures ${ }^{(4,8)}$.

Till present there are not enough clinical studies to compare different partial denture frameworks and base material $^{(9)}$. 


\section{MATERIAL AND METHODS}

Twelve patients ranged from 45-60 year old (6 males and 6 female) came to the department of prosthodontics, Alexandria University with past medical history. They had no medical problems. Past dental history: they extracted many teeth, all because of dental caries. Extractions were simple without problems. The patient complains from pain in some teeth inability to masticate and chew her food and unsatisfactory esthetic, so they need to have prosthesis to eat on. No clicking or pain during opening and closing her mouth. Intra-oral examination: Clinical examination: normal appearance in mucosa. There are multiple missing teeth, the upper jaw is class III Kennedy classification with modification 2, the lower jaw is class I Kennedy classification without modification.

From radiographs and clinical examinations, there are multiple teeth needing restorations.

- Phase 1: Diagnostic phase:

Taking alginate primary impressions, surveying the upper and lower study casts, occlusal analysis and diagnostic wax up.

- Phase II: Prosthetic and restorative phase:

1. Endodontic treatments and other simple fillings of carious teeth. Drawing the designee for the metalic bases.

2. Preparations of bilateral $\mathrm{L} / \mathrm{r} 4$ and 5 to have crowns.

3. Upper and lower final impressions poring the master cast jaw relation record and face bow transfer.

4. Try-in of L/Lt crowns on prepared teeth.

5. Fabrication of upper acrylic and lower attachments with metallic frameworks to connect the casted metal crowns and attachments.

The diagnostic wax-up was completed and the RPD was designed.
- A putty matrix impression material was made.

- Maxillary teeth were prepared and full contour wax-up made.

- The crowns were fabricated and veneered.

- A pick-up impression of fixed components was made and poured to obtain the cast.

- The partial denture wax-up was done conventionally. Caution was taken when the patrix was covered with the wax.

Phase III: Definitive treatment, Try-in in patient's mouth. Insertion of the attachments and crowns. Try in, metalic base metal insertion then occlusal adjustment.

- After the patient's approval of the waxed-up RPD, they were acrylized and inserted.

Phase IV: Maintenance phase, Post insertion care, Oral hygiene, Periodic recall. Continual periodic follow- up to monitor the function and maintenance of the partial denture was done.

The patient was instructed about correct insertion and removal of the finished dentures and preservation of good oral hygiene. Periodic followup was carried out.

Two lines were drawn, one tangential to the mandibular inferior edge and the other at equal distance to it and about $10 \mathrm{~mm}$ above it. It was found that, in dentate patients, the first premolar and the first molar were located at approximate position of 35 and $55 \%$ from the midline to the mandibular body.

The present study aims to evaluate clinically the effect of using evaluation of ball type precision attachment for lower class I Kennedy classification using new computerized method and its effect on the bone height and changes at different sites $(10,11)$. Figure $(1,2)$ 


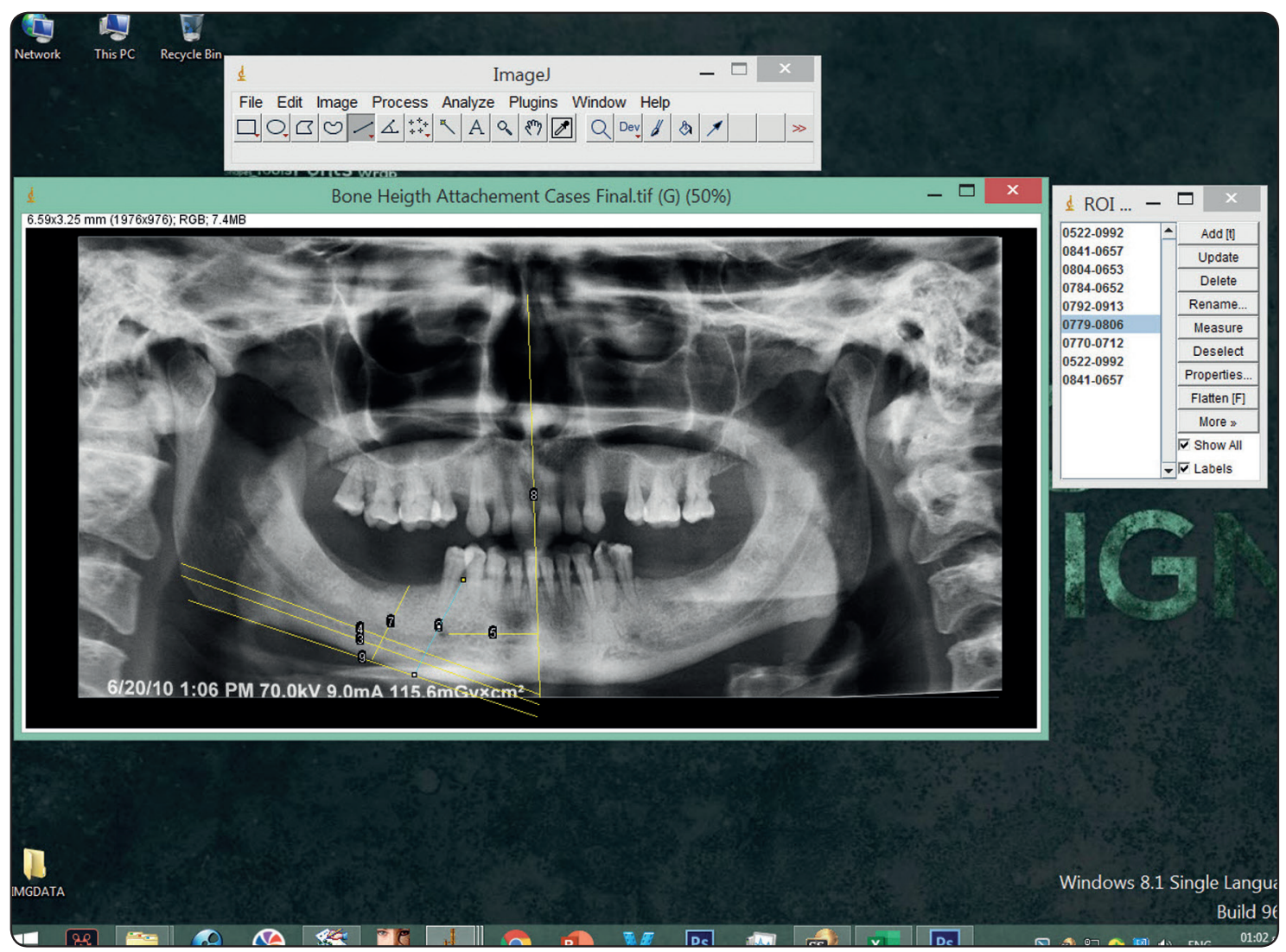

Fig. (1): Measurements on the panoramic radiograph. Mandibular bone measurements were made with the technique proposed by Wical and Swoope.9 1, Line parallel to long axis of mandible and tangential to inferior border of mandible was drawn. 2, Line perpendicular to this tangent intersecting inferior border of mental foramen was constructed, along which the following measurements were made: A, Lower border to top of alveolar crest: total height of the mandible; B, distance from lower border to inferior edge of mental foramen: basal height; $\mathrm{C}$, thickness of mandibular cortex (So, in our study we measured the $(\mathrm{C})$ of the mandibular cortex). These measurements were made on both sides of the mandible.

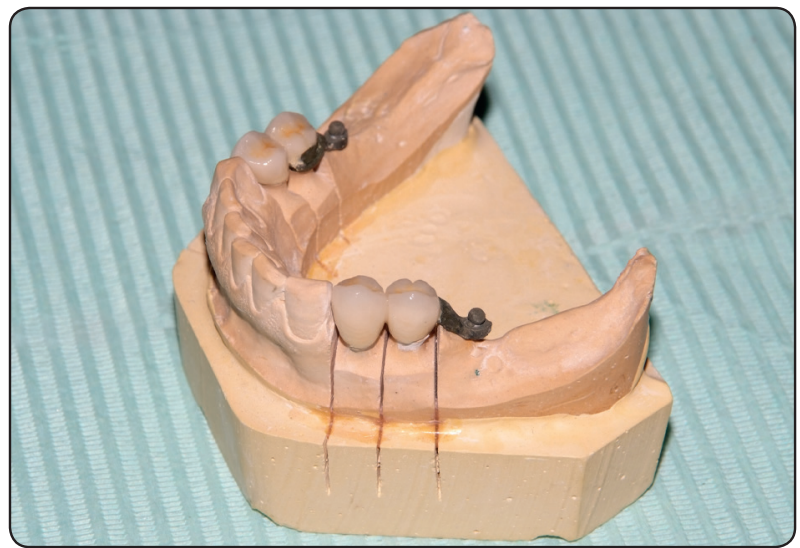

Fig. (2): Casted crown and ball type attachment on the master cast.

\section{RESULTS}

Assessment of alveolar bone height at different sites of the mandibular alveolar bone midline (ML), first premolar (FP), first molar (FM) and bone thickness $(\mathrm{C})$ as reference points for ball type precision attachment used for lower class I Kennedy classification.

Assessment is done by using a new computerized method image $\mathbf{J}$ program which not used in other previous studies and comparing between the differences between the two groups (male and female) as regards to age and gender.

There was no statistically significance difference between right and left sides for male and female groups. (Table 1,2,3) 
TABLE (1): Patients' satisfaction about the prosthesis in relation to function and prosthetic were recorded.

\begin{tabular}{|c|c|c|c|c|}
\hline & \multicolumn{2}{|c|}{ Function } & \multicolumn{2}{|c|}{ Esthetic } \\
\hline & Yes & No & Yes & No \\
\hline \multicolumn{5}{|c|}{ At $1^{\text {st }}$ month } \\
\hline Male & 2 & 4 & 3 & 3 \\
\hline Female & 3 & 3 & 4 & 2 \\
\hline \multicolumn{5}{|c|}{ At $6^{\text {th }}$ months } \\
\hline Male & 1 & 5 & 5 & 1 \\
\hline Female & 1 & 5 & 4 & 2 \\
\hline \multicolumn{5}{|c|}{ At $12^{\text {th }}$ months } \\
\hline Male & 6 & 0 & 6 & 0 \\
\hline Female & 6 & 0 & 6 & 0 \\
\hline
\end{tabular}

TABLE (2): Distribution of the studied cases according to gender and age $(n=12)$

\begin{tabular}{lc}
\hline & No. $(\%)$ \\
\hline Gender & $6(50 \%)$ \\
Male & $6(50 \%)$ \\
Female & \\
Age (years) & $49.7 \pm 5.7$ \\
Mean \pm SD. & $47(45-59)$ \\
Median (Min. - Max.)
\end{tabular}

TABLE (3): Comparison between males and females according to length of bone height

\begin{tabular}{|c|c|c|c|c|c|c|c|}
\hline & \multirow{2}{*}{ Length of bone height } & \multicolumn{2}{|c|}{ Right } & \multicolumn{2}{|c|}{ Left } & \multirow[b]{2}{*}{$\mathbf{p}_{1}$} & \multirow[b]{2}{*}{$\mathbf{p}_{2}$} \\
\hline & & Male $(n=6)$ & Female $(n=6)$ & Male $(n=6)$ & Female $(n=6)$ & & \\
\hline \multirow{6}{*}{$\sum_{\mid=}$} & At Baseline & $16.6 \pm 2.7$ & $16.7 \pm 2.9$ & $17.2 \pm 2.2$ & $15.4 \pm 2.1$ & 0.459 & 0.166 \\
\hline & $\mathbf{t}(\mathbf{p})$ & \multicolumn{2}{|c|}{$0.084(0.935)$} & \multicolumn{2}{|c|}{$1.457(0.176)$} & & \\
\hline & After 6 months & $15.8 \pm 2.8$ & $15.5 \pm 2.9$ & $16.4 \pm 2.3$ & $14.7 \pm 2.4$ & 0.527 & 0.395 \\
\hline & $\mathbf{t}(\mathbf{p})$ & \multicolumn{2}{|c|}{$0.208(0.840)$} & \multicolumn{2}{|c|}{$1.194(0.260)$} & & \\
\hline & After 12 months & $15.7 \pm 2.8$ & $15.3 \pm 2.8$ & $18 \pm 4$ & $14.3 \pm 2.4$ & 0.170 & 0.204 \\
\hline & $\mathbf{t}(\mathbf{p})$ & \multicolumn{2}{|c|}{$0.217(0.833)$} & \multicolumn{2}{|c|}{$1.938(0.081)$} & & \\
\hline \multirow{6}{*}{$\hat{x}$} & At Baseline & $20.2 \pm 1.5$ & $19.6 \pm 1.9$ & $19.3 \pm 2.2$ & $19.1 \pm 2.6$ & 0.354 & 0.158 \\
\hline & $\mathbf{t}(\mathbf{p})$ & \multicolumn{2}{|c|}{$0.680(0.512)$} & \multicolumn{2}{|c|}{$0.172(0.867)$} & & \\
\hline & After 6 months & $19.5 \pm 1.5$ & $18.2 \pm 2.2$ & $18.7 \pm 2.2$ & $18 \pm 2.8$ & 0.391 & 0.605 \\
\hline & $\mathbf{t}(\mathbf{p})$ & \multicolumn{2}{|c|}{$1.256(0.238)$} & \multicolumn{2}{|c|}{$0.460(0.655)$} & & \\
\hline & After 12 months & $19.1 \pm 1.6$ & $17.7 \pm 2$ & $18.1 \pm 2.1$ & $17.7 \pm 2.9$ & 0.310 & 0.894 \\
\hline & $\mathbf{t}(\mathbf{p})$ & \multicolumn{2}{|c|}{$1.349(0.207)$} & \multicolumn{2}{|c|}{$0.340(0.741)$} & & \\
\hline \multirow{6}{*}{ 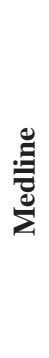 } & At Baseline & $20.2 \pm 0.6$ & $18.9 \pm 3$ & $20.1 \pm 1$ & $18.9 \pm 3.2$ & 0.816 & 0.765 \\
\hline & $\mathbf{t}(\mathbf{p})$ & \multicolumn{2}{|c|}{$1.047(0.340)$} & \multicolumn{2}{|c|}{$0.923(0.392)$} & & \\
\hline & After 6 months & $19.2 \pm 0.7$ & $17.8 \pm 3.1$ & $19.2 \pm 1$ & $17.7 \pm 3.3$ & 0.887 & 0.766 \\
\hline & $\mathbf{t}(\mathbf{p})$ & \multicolumn{2}{|c|}{$1.130(0.305)$} & \multicolumn{2}{|c|}{$1.030(0.344)$} & & \\
\hline & After 12 months & $19 \pm 0.8$ & $17.4 \pm 3.2$ & $18.9 \pm 1$ & $17.1 \pm 3.1$ & 0.888 & 0.365 \\
\hline & $t(p)$ & \multicolumn{2}{|c|}{$1.137(0.301)$} & \multicolumn{2}{|c|}{$1.292(0.225)$} & & \\
\hline
\end{tabular}




\begin{tabular}{|c|c|c|c|c|c|c|c|}
\hline \multirow{6}{*}{ U } & At Baseline & $20.8 \pm 1.7$ & $20.8 \pm 1.9$ & $19.8 \pm 2$ & $20.8 \pm 2.3$ & $0.004^{*}$ & 0.952 \\
\hline & $\mathbf{t}(\mathbf{p})$ & \multicolumn{2}{|c|}{$0.002(0.999)$} & \multicolumn{2}{|c|}{$0.787(0.449)$} & & \\
\hline & After 6 months & $20 \pm 1.9$ & $19.6 \pm 2.4$ & $19.3 \pm 1.6$ & $19.4 \pm 2.5$ & 0.072 & 0.613 \\
\hline & $\mathbf{t}(\mathbf{p})$ & \multicolumn{2}{|c|}{$0.352(0.732)$} & \multicolumn{2}{|c|}{$0.048(0.963)$} & & \\
\hline & After 12 months & $19.6 \pm 1.8$ & $19.2 \pm 2.3$ & $19 \pm 1.6$ & $18.6 \pm 2.1$ & 0.136 & 0.101 \\
\hline & $\mathbf{t}(\mathbf{p})$ & \multicolumn{2}{|c|}{$0.322(0.754)$} & \multicolumn{2}{|c|}{$0.404(0.695)$} & & \\
\hline \multirow{6}{*}{ 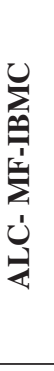 } & At Baseline & $19.8 \pm 1.3$ & $19.3 \pm 1.9$ & $18.8 \pm 2.5$ & $19.1 \pm 2.2$ & 0.123 & 0.232 \\
\hline & $\mathbf{t}(\mathbf{p})$ & \multicolumn{2}{|c|}{$0.540(0.601)$} & \multicolumn{2}{|c|}{$0.235(0.819)$} & & \\
\hline & After 6 months & $19.1 \pm 1.4$ & $18.2 \pm 1.9$ & $17.9 \pm 2.6$ & $18 \pm 2.1$ & 0.108 & 0.395 \\
\hline & $\mathbf{t}(\mathbf{p})$ & \multicolumn{2}{|c|}{$0.967(0.356)$} & \multicolumn{2}{|c|}{$0.076(0.941)$} & & \\
\hline & After 12 months & $18.7 \pm 1.4$ & $18 \pm 2$ & $17.7 \pm 2.5$ & $17.8 \pm 2.1$ & 0.232 & 0.258 \\
\hline & $\mathbf{t}(\mathbf{p})$ & \multicolumn{2}{|c|}{$0.623(0.547)$} & \multicolumn{2}{|c|}{$0.106(0.917)$} & & \\
\hline \multirow{6}{*}{ 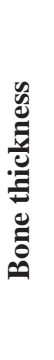 } & At Baseline & $2.5 \pm 0.1$ & $2.6 \pm 0.5$ & $2.4 \pm 0.3$ & $2.5 \pm 0.4$ & 0.530 & 0.398 \\
\hline & $t(p)$ & \multicolumn{2}{|c|}{$0.578(0.576)$} & \multicolumn{2}{|c|}{$0.539(0.601)$} & & \\
\hline & After 6 months & $2.5 \pm 0.1$ & $2.5 \pm 0.5$ & $2.4 \pm 0.4$ & $2.5 \pm 0.4$ & 0.493 & 0.767 \\
\hline & $t(p)$ & \multicolumn{2}{|c|}{$0.080(0.939)$} & \multicolumn{2}{|c|}{$0.527(0.610)$} & & \\
\hline & After 12 months & $2.5 \pm 0.1$ & $2.4 \pm 0.5$ & $2.3 \pm 0.4$ & $2.4 \pm 0.4$ & 0.400 & 0.778 \\
\hline & $\mathbf{t}(\mathbf{p})$ & \multicolumn{2}{|c|}{$0.376(0.721)$} & \multicolumn{2}{|c|}{$0.428(0.678)$} & & \\
\hline
\end{tabular}

Data was expressed by using Mean $\pm S D$.

t: Student t-test

p: p value for comparing between males and females

p1: p value for Paired t-test for comparing between Right and Left in Male

p2: p value for Paired t-test for comparing between Right and Left in female

*: Statistically significant at $p \leq 0.05$

\section{DISCUSSION}

Residual ridge resorption is usually more slower in the anterior region than in the premolar and molar region of the mandible as the results of the finding of the reversal line in the posterior region of the mandible present at the side of the toung and the mylohyoid ridge ${ }^{(12)}$. The present of attachment causing the functional forces and so at protecting this area from sever alveolar bone loss and decrease in vertical height. According to the results of Mercier ${ }^{(12)}$ and Xie et al ${ }^{(13)}$ found that the first premolar and first molar sites. Give more decrease in the height of the mandibular bone that agrees with our study. The elevation of the mandibular alveolar bone at the anterior, first premolar, and first molar regions were markedly increase in male and female groups except at first molar region, anterior and first premolar regions findings were identical to that in the study by Sağlam ${ }^{(14)}$.

According to the clinical need and demand, restoration of the lost structure can be restorted by using conventional methods ${ }^{(15)}$. The aim of prosthetic treatment reconstruction is to preserve and restore health, aesthetics, and function ${ }^{(16)}$. 
A full-arch fixed prosthesis can be constructed, if adequate and properly situated abutments remain or adequate mean for support and retention can be placed $^{(17)}$.

Because clasps interfere with aesthetic which are required in the anterior area, which not found with the use the attachments and so they gave the same function as that of the clasps, i.e., to provide retention and connection of the needed prosthesis to the natural teeth ${ }^{(18)}$.

But it required excessive tooth reduction and not less than $3 \mathrm{~mm}$ of height which considered as disadvantage of the intracoronal type ${ }^{(19)}$.

The extracoronal resilient attachments which indicated for RPD is usually deficient of the space for the attachment, so that the denture tooth can be placed over it. Also, the small type attachments available in the market, take place a great amount of edentulous space found posterior to the abutment tooth ${ }^{(20)}$. The CPA, in this case, contains two parts; male and female. The guide plane was found in the patrix and the rest in the matrix. The housing contain a rest and guide planes as basic parts of the RPD.

This clinical record describes a method of removal the display of metal on the labial surface of maxillary anterior teeth used as abutments for a RPD, by using a CPA.

In general, the more precise or rigid the attachment design is, the greater is the degree of indirect retention inherent in the design. Additionally, the more widely spaced the retainers are, the greater the support and stability are when compared with a design with retainers placed closely together ${ }^{(2)}$.

Gupta et al. ${ }^{(21)}$, found that precision attachment such as RHEIN 83 OT CAP attachments system can be used to improve retention, esthetics, and function of RPD and this agrees with our study.

Soni et al. ${ }^{(22)}$, showed that combined prosthesis is consists of fixed prosthesis (crown) and removable prosthesis (acrylic partial denture) which are attached with each other by an attachment system
(OT Unilateral, Rhein 83, USA). Our study agrees with this study.

The use of RPD in usually to improve patients' function for mastication and get patient satisfaction and improve quality of life ${ }^{(23)}$.

The difference in the resiliency of periodontal ligament of abutment teeth and denture bearing mucosa. Causes uneven transmit of the vertical forces to the underlining tissue when unilateral distal extension was used ${ }^{(24)}$.

Elsyad., et al. ${ }^{(25)}$ who reported in their invitro study that the "resilient" configuration allows for more movements of the denture therefore, more stresses will be used on the abutment teeth.

In group A (male), the mean bone elevation circling abutment teeth reduction gradually with advance of time and between intervals. In group $B$ (female), the mean bone elevation circling the abutment teeth was also increased at baseline and reduced gradually through the six months to record the minimal value during the twelve months.

The continuous reduction in bone elevation circling the abutment teeth may be attributed to the continuous denture base settlement during the first few months; this may result in decrease motion of the denture base with time which contributes to more resistance to the rotational and lateral movements and so decreased stresses on abutment teeth and decreased bone resorption ${ }^{(26)}$.

The mean crestal bone loss surrounding abutment teeth in OT-equator attachment was higher when compared to ball attachment. SEM analysis confirmed that wear rate depends primarily on contact area and is directly proportionate to it. This may explain that a female section of the OT-equator attachment was subjected to wear greater than the retentive female caps of the attachments as a result of greater denture base movement ${ }^{(27)}$. This explanation is accepted by Wolf et al. ${ }^{(28)}$ who concluded that the ball attachment provide better retention and better resistance to wear on the extended term in comparison to resilient attachments. 
Conversely, Mahrous., et al. (29) concluded that there was insignificant variance in the mean abutment alveolar bone resorption connecting between a resilient low profile attachment and the ball attachment after 6 months which not be found in the present study. This conflicting as a result of using RPI clasp in their study that can transmit less stresses to the abutment teeth as concluded by Abd-Elkhalek., et al. ${ }^{(30)}$. The consequence of the opposing arch and the occlusal scheme may be of a concern in each study.

Because the occluso-gingival height of the attachment may affect the biomechanics of the delivered prosthesis, many authors reported that low profile attachment with small diameter help in decreasing stresses on supported abutment and directing more forces toward tooth abutments supporting RPD ${ }^{(31)}$. However, in another in vitro research that used ball attachments for IADERPOD, the authors found a more decreased strain circling abutment teeth for IADEPOD with ball attachments ${ }^{(25)}$.

Bollen et al (11) concluded that thinning of the mandibular lower cortex. And Al-Jabrah, (32), compared bone residual ridge resorption in diabetic and nondiabetic patients, and found that case of osteporosic had tendency to get bone resorption and the mean mandibular resorption in diabetic group was found to be more increase in quantity in relation to nondiabetics cases.

\section{CONCLUSIONS}

The administration of attachments for partial edentulous condition are the valuable treatment option when other treatment options are not indicated like fixed partial denture. For improving function ability of mastication, showing and good esthetic acceptance of RPD. The utilization of ball type attachment provide good retention support and stability to it.

Ball attachments causes limitation when used to retain partial denture to other supporting mean that may leads to alveolar bone resorption circling abutment teeth than OT-equator attachment and to improved longevity of the natural tooth using of ball type attachment may be indicated as a suitable choice.

Preservation of bone by the constant stimulation of supporting tissue by biting force recovers appearance and patient satisfaction low cost for the patient than treatment by other expensive prosthesis.

Residual ridge resorption is usually less rapid in the anterior region of the mandible than the premolar and molar region because of the reversal line is found in a lower position.

The elevation of the mandible at the anterior (ML), first premolar (FP), and first molar (FM) areas were significantly smaller in women than in men.

The ball type attachment has the minimal vertical height and diameter for the overdenture abutment available in the market.

The ball attachment provided superior retention and superior withstand to wear on the extended term in comparison to resilient attachments.

Decreased strain surrounding abutment teeth by using ball attachments.

As the results of osteoporotic fractures due to porous mandibular cortex detected by the panoramic $\mathrm{x}$-ray in the dentate patients which increase by age even when all the other factors as sex, Age, height and weight, smoking and present teeth were adigusted it was found that an osteoporotic fracture are more increase in reported cases which have medium or excessive erosion in its cortex that found under the mental foramen.

In case of using ball type attachment, the measurements of vertical height in the edentulous men were increased than that of the women statistically. Vertical measurements using panoramic radiographs were clinically applicable in quantitative assessment of alveolar bone height in the mandible. 


\section{REFERENCES}

1. Dhumal P. Attachment supported dentures. IOSR-JDMS. 2019;18:72-6.

2. Makkar S, Chhabra A, Khare A. Attachment retained removable partial denture: A Clinical Report. IJCDS. 2011;2:39-43.

3. Arti AG, Khanna G, Bhatnagar M, Markose GM, Singh S. Precision Attachments in Prosthodontics: A Review. Int J Prev Clin Dent Res. 2018;5:34-9.

4. Jones JD, García LT. Removable partial dentures: A clinician's guide. Ames, Iowa: Wiley-Blackwell; 2009.

5. Arce-Tumbay J, Sanchez-Ayala A, Sotto-Maior BS, Senna PM,Campanha NH. Mastication in subjects with extremely shortened dental arches rehabilitated with removable partial dentures. Int J Prosthodont. 2011;24:517-9.

6. Macura-Karbownik A, Chladek G, Żmudzki J, Kasperski J. Chewing efficiency and occlusal forces in PMMA, acetal and polyamide removable partial denture wearers. Acta Bioeng Biomech. 2016;18:137-44.

7. Bilhan H, Geckili O, Mumcu E, Cilingir A, Bozdag E. The influence of implant number and attachment type on maximum bite force of mandibular overdentures: a retrospective study. Gerodontology. 2012;29:116-20.

8. Preiskel HW, Preiskel A. Precision attachments for the $21^{\text {st }}$ century. Dent Update. 2009;36:221-4, 226-7.

9. El Khourazaty N, Darwish ET. Evaluation of bone height changes and biting forces in distal extension prosthesis with different denture base materials. EDJ. 2018;64:1397404.

10. Güler AU, Sumer M, Sumer P, Biçer I. The evaluation of vertical heights of maxillary and mandibular bones and the location of anatomic landmarks in panoramic radiographs of edentulous patients for implant dentistry. J Oral Rehabil. 2005;32:741-6.

11. Bollen AM, Taguchi A, Hujoel PP, Hollender LG. Casecontrol study on self-reported osteoporotic fractures and mandibular cortical bone. Oral Surg Oral Med Oral Pathol Oral Radiol Endod. 2000;90:518-24.

12. Güler AU, Sumer M, Sumer P, Biçer I. The evaluation of vertical heights of maxillary and mandibular bones and the location of anatomic landmarks in panoramic radiographs of edentulous patients for implant dentistry. J Oral Rehabil. 2005;32:741-6.
13. Panchbhai AS. Quantitative estimation of vertical heights of maxillary and mandibular jawbones in elderly dentate and edentulous subjects. Spec Care Dentist. 2013;33:62-9.

14. Sağlam AA. The vertical heights of maxillary and mandibular bones in panoramic radiographs of dentate and edentulous subjects. Quintessence Int. 2002;33:433-8.

15. Heckmann SM, Schrott A, Graef F, Wichmann MG, Weber HP. Mandibular two-implant telescopic overdentures- 10 year clinical and radiographical results. Clin Oral Implant Res. 2004;15:560-9.

16. D〉Souza D, Dua P. Rehabilitation strategies for partially edentulousprosthodontic principles and current trends. Med J Armed Forces India. 2011;67:296-8.

17. Zitzmann NU, Rohner U, Weiger R, Krastl G. When to choose which retention element to use for removable dental prosthesis. Int J Prosthodont. 2009;22:161-7.

18. Shillingburg HT Jr, Hobo S, Whitsett LD, Jacobi R, Brackett SE. Fundamentals of fixed prosthodontics. $4^{\text {th }}$ ed. Chicago: Quintessence; 2012.

19. Badwaik PV, Pakhan AJ. Non-rigid connectors in fixed prosthodontics: Current concepts with a case report. J Indian Prosthodont Soc. 2005;5:99-102.

20. Goto Y, Brudvik JS. Custom precision attachment housings for removable partial dentures. J Prosthet Dent 2002;88:100-2.

21. Gupta N, Bhasin A, Gupta P, Malhotra P. Combined prosthesis with extracoronal castable precision attachments. Case Rep Dent. 2013;2013:282617.

22. Soni R, Yadav H, Priya A. Combined prosthesis with precision attachment for distal extension kennedy class II arch: A case report. Indian J Sci Res. 2018;20:126-8.

23. Sato M, Suzuki Y, Kurihara D, Shimpo H, Ohkubo C. Effect of implant support on mandibular distal extension removable partial dentures: Relationship between denture supporting area and stress distribution. J Prosthodont Res. 2013;57:109-12.

24. Liu R, Kaleinikova Z, Holloway JA, Campagni WV. Conversion of a partial removable dental prosthesis from Kennedy Class II to Class III using a dental implant and semiprecision attachments. J Prosthodont. 2012;21:48-51.

25. ELsyad MA, Omran AO, Fouad MM. Strains surrounding abutment teeth with different attachments used for implant-assisted distal extension partial overdentures: An in vitro study. J Prosthodont. 2017;26:42-7. 
26. Abdelmoez AM, Fouad MM, Abdel-Khalek EA. The effect of two different solitary attachments used to retain implant assisted mandibular distal extension Removable Partial Overdenture on abutment alveolar bone height changes. MJD. 2018;5:29-34.

27. Mahross HZ, Baroudi K. Evaluation of retention and wear behavior for different designs of precision attachments. Oral Health Dent Manag. 2015;14:244-9.

28. Wolf K, Ludwig K, Hartfil H, Kern M. Analysis of retention and wear of ball attachments. Quintessence Int. 2009;40:405-12.

29. Mahrous AI, Aldawash HA, Soliman TA, Banasr FH, Abdelwahed A. Implant supported distal extension over denture retained by two types of attachments. A comparative radiographic study by cone beam computed tomography. J Int Oral Health. 2015;7:5-10.

30. Abd El-Khalck M, Aldeen MAS, EI-makawee N. Stress releasing clasp assemblies design related to abutment alveolar bone resorption. EDJ. 2006;52:1785-95.

31. AMMAR NA, El-Khodary NM, Abdelhamid AM. Clinical evaluation of the implant retained overdenture with OTequator attachments. Int J Sci Res. 2016;5:643-7.

32. Al-Jabrah O. Association of type 2 diabetes mellitus with the reduction of mandibular residual ridge among edentulous patients using panoramic radiographs. OJST. 2011;1:61. 